I think that the isolated quantum of radiant energy can only be considered in radiations of very high frequency (when Wien's law is valuable), but that for radiations of mean or low frequencies we must conceive a sort of aggregation of light quanta. This idea suggested by the form of Planck's law would perhaps allow us to imagine a transition between light quanta and electromagnetic theory and to avoid Mr. Anderson's conclusion.

$$
\text { June I4. }
$$

$$
\text { Louis DE BROGLIE. }
$$

\section{Cell Inclusions in the Gametogenesis of Scorpions.}

SINCE last winter I have been engaged on the study of cell-inclusions in the gametogenesis of scorpions, and it was, therefore, with some interest that I read the note of Profs. D. R. Bhattacharya and J. B. Gatenby on the spermatogenesis of an Indian scorpion (Palamnæus) published in NATURE, June I4.

I have studied mitochondria in the spermatogenesis of Palamneus fulvipes madraspatensis, and can confirm the following statements of the writers :

(I) "The mitochondria are sorted out whole during the maturation stages." This is true of both the meiotic divisions.

(2) "The number of mitochondria varies in the spermatid."

In Palamnaus fulvipes madraspatensis the number varies from four to thirteen.

I am, however, unable to support the statement that "the mitochondria form the sperm tail directly. .. "During a certain stage in spermateleosis the mitochondria are grouped together at the base of the elongated nucleus. To a large extent they lose their individuality and form a curious oval body-the mitosome-which stains characteristically with crystal violet, Altman's acid fuchsin and iron hæmatoxylin. I have not been able to detect the mitochondria after this stage. Nor have I seen them at any stage descending down the axial filament.

I may here add a note on the mitochondria of the oocyte of the same species. They are remarkably different in their reaction to osmic acid from those of the male germ cells. There is no case on record where the mitochondria are blackened by chrome-osmium alone. Where they are blackened, it is only after prolonged osmication (Kopsch). But the mitochondria in the oocyte are intensely blackened by chrome-osmium alone in ten hours. They are even preserved and blackened by Fleming-with-acetic acid. They can be decolorised by turpentine, but subsequent staining is impossible. They are completely destroyed by Bouin's fluid. These facts undoubtedly suggest the presence of a large amount of unsaturated fat in the mitochondria.

The Golgi apparatus in the oocyte of the same species consists of rods and crescents distributed in patches.

I hope to publish in due course a paper on the cell inclusions in the gametogenesis of Palamnæus (Madras), Buthus judaicus and Heterometrus maurus (Palestine), and Euscorpius napoli (Naples).

Zoological Laboratory, Cambridge, VISHWA NATH. June 20 .

\section{Art-Forms in Nature.}

Permit me to thank Mr. Edward Heron-Allen for the very generous reference to my work published in his review of Haeckel's "Kunstformen der Natur" (Nature, June 14, p. 847). Mr. Heron-Allen says: "A law only approximates to the facts, and every time we use it we have to make appropriate additions and corrections; the real value of deviations is not that they make it necessary to discard a theory, but that they enlarge our laws and thereby advance our knowledge." This sentence formed part of an appreciation of my book, "The Curves of Iife," which was published in I9I4. With your permission I will quote a short passage from this book which gives an excellent example of the process mentioned, an example which in 1924 we can all read with a startling verification in our minds.

"The principle enunciated by Newton," I wrote on pp. 429 and 430 , " may ' simplify' the phenomena of our solar system sufficiently to enable us to talk about the movements of the earth and the celestial bodies. But that simplicity, we may feel sure, is only apparent. Newton himself, as far as I am aware, never ventured to suggest any 'cause' for his great principle. We may well consider that its value as a working hypothesis outweighs the possibilities of its inexactness. But we must be equally prepared to realise that it may not fit all the facts which future science may discover. It is, in $\mathrm{H}$. Poincaré's admirable phrase, une règle d'action qui réussit; or, in other words, we have added (I9I4) so few phenomena of real importance to those known by Newton that the basis furnished by his ' law' has not yet been disintegrated. But it is easily conceivable that a broader foundation will be needed, even in the present century; and we need have no fear that men of science will shrink from the endeavour to provide it. The sterile reprobation of Auguste Comte (who was obsessed by sociological ideas of 'Order') has long ago become inoperative."

These lines were written ten years ago, and I freely admit that logic had more to do than special knowledge with a prophecy which Einstein was so soon and so brilliantly to fulfil.

Savile Club, ro7 Piccadilly, W. June I9.

\section{The Oogenesis of Lithobius.}

THE oogenesis of the Arthropoda is the least well understood, because it has presented considerable technical difficulties. In this country Hogben has investigated successfully the oogenesis of dragonflies, and has shown that the nucleolus takes important direct part in the production of the yolk spheres.

The oogenesis of Lithobius appears to be much like that of Hogben's examples, and is probably general for Arthropoda. Yolk formation is from nucleolar extrusion, of which two phases can be distinguished; first, an early extrusion of particles budded off from the large central nucleolus, which retains its individuality, and, secondly, an extrusion of particles derived from the fragmentation of this nucleolus. These particles multiply both in the nucleus and in the cytoplasm. The fate of the first nucleolar extrusions has not been determined, but the later extrusions enlarge after proliferation to form the definitive yolk spheres. The Golgi apparatus behaves in the usual way, being excentric and juxta-nuclear in the youngest oocytes, then spreading out through the cell, and breaking eventually into very fine grains. The mitochondria are diffuse in the earliest stages, then become concentrated to a cloud near the nucleus; this breaks up into a number of clusters, some of which become active centres of proliferation. These form curious round mitochondrial bodies, which later fragment, the mitochondria passing out to become evenly distributed through the cytoplasm. The clouds which did not take part in the rapid proliferation also become scattered at the same time. A full account of the oogenesis will be published later.

Zoological Department,

$$
\text { NO. } 2854 \text {, VOL. I I } 4]
$$

